\title{
La autoridad en Jesús
}

\section{José Ignacio González Faus, Sant Cugat del Vallés, Barcelona. Centro de Reflexión Teológica, San Salvador.}

Nadie podrá negar que la autoridad es hoy un tema controvertido, nadie podrá negarlo. $Y$ esa controversia abarca tanto el campo antropológico como el teológico, tanto el ético como el religioso.

El hombre modemo ha hecho algunas de sus experiencias más escalofriantes procisamente en tomo a la autoridad. Y al antiguo vérigo del caos y de la anarquía se le ha sumado en nuestro siglo otro vérugo igualmente sobrecogedor: porque el hombre ha contemplado el abismo de degradación a que puede conducir no sólo un determinado ejercicio de la autoridad, sino una determinada forma de obediencia.

Nazismos, estalinismos, pot-poltismos y otras variadas formas de terrorismo del poder pucden ser evocados aquí como testimonios de la defensa para esta tesis que constituye nuestro punto de partida: el trauma de la ausoridad se ha convertido en un daw importante de nuestras psicologías, con el que es preciso contar.

No pretendo decir aquí que este trauma nos haya hocho olvidar el otro "shock" de la anarquía. (Basta con evocar las voces que crispadamente reclaman "mano dura" - 0 incluso venganza - ante amenazas como la inseguridad ciudadana o el terrorismo). Lo que digo es que las cosas se nos han complicado: que hay que operar con dos factores que parecen destruirse el uno al otro; y que esto tiende a polarizar las posiciones. Los creyentes pueden seguir cantando que "donde hay caridad y amor, allí está Dios"; pero todas las instituciones religiosas siguen pensando que donde hay autoridad y orden, alll es donde realmente está Dios. Algunos cristianos pueden repetir aquello tan sabio de que "la gloria de Dios es que el hombre viva"; pero ouros (si se me permite el chiste) seguirán hablando y actuando como si pensaran que "la gloria de Dios es que mande el obispo"... Y en todas estas insinuaciones maliciosas no eswy reco- 
giendo sólo factores antropológicos, sino algo todavía más serio: la posibilidad de un cambio en las mediaciones teofánicas: poder, orden y seguridad (que son factores de conservación), o amor, libertad y riesgo (que son faclores de creación).

Pero ¿se trata efectivamente de un cambio o de una vuelta purificadora a los orfgenes? ¿Que responderfa un cristiano a este modo de plantear las cosas?

He aquí la pregunta decisiva, que habria que dilucidar un poco más despacio en el presente artículo. Nos vamos a fijar sólo en Jesús, el Seffor, la verdadera y única autoridad de lodo cristiano'. Con todo, no queremos hacer un trabajo de investigación histórica, sino sólo una lectura del texto evangélico. Sabemos que la imagen que surge de ese texto es globalmente fidedigna, aunque tal o cual rasgo particular puedan estar históricamente desfigurados o "aplicados" a una situación nueva. Y sabemos también que, dada la optica "post-pascual" desde la que escriben los evangelios, sus aulores habrán tenido más interés en "hinchar" la imagen de autoridad de Jesús que en rebajarla.

En cualquier caso, Jesús parece habernos dicho que "el discípulo no es mayor que su Mestro" (Mt 10, 24) y que "Yo, a quien usledes llaman Sefior y Maestro, les he dado ejemplo para que obren del mismo modo" (Jn 13,15). Ahí estí puesta la ilusión del presente artículo: ¿cuál es ese ejemplo de Jesús?

Por eso no preguntamos únicamente qué enseftaba o qué parece pensar Jesús sobre las otras autoridades, sino qué decía sobre su propia autoridad y cómo la ejerclig. Esto último es lo más importante, y todo lo anterior quiere ser un medio para esto segundo: pues probablemente nos ayudará a tener un marco hermentutico para comprender algunas conductas de Jesús, de acuerdo con eso que los estudiosos del Nuevo Testamento suelen lamar "criterio de coherencia".

Es lógico, además, emprender esta búsqueda, porque los evangelios parecen conservar huellas reales de un asombro producido por Jesús en este punto: se dice que El no hablaba (ni obraba) "como las autoridades religiosas del pueblo" (ver Mt 7, 28; Mc 1, 27), sino con una especial libertad y una especial "autoridad", que no consistian en dictar, sino en convencer, no en apelar a justificaciones externas (la Ley, etc.), sino a la verdad misma de lo que decía.

Pero esto es lo que hemos de ver un poco más despacio en las páginas que siguen. Ya han quedado establecidas sus partes principales: el juicio de Jesús sobre las autoridades, su enserlanza positiva sobre la autoridad y su praxis concreta en este diffcil punto. El resto (lo que diremos sobre la llamada al seguimiento y sobre la reacción provocada por Jesús) quiere ser sólo complemento que ojala ayude a percibir la coherencia de todo lo demás. 


\section{Lo crítka a los poderes existentes}

\section{Lo autoridad civil}

Esle punto importa menos para nuestra reflexión, pero conviene comenzar por el, porque dará lugar al punto siguiente.

El texto clásico es Lucas 22, 25-30 (par. Mc 10, 42-45), cuyo resumen es: las autoridades "mundanas" hacen llamar "servicio" a su dominio. La clave del texio radica en la contraposición entre kyrieuô (dominar, enseforearse) y euergete $\delta$ (servir, favorecer); la autoridad "mundana" no convierte su poder en servicio, sino que simplemente llama "servicio" a su propio poder; no cambia el ejercicio del poder, sino que cambia solo el nombre.

Pero esta critica al poder "mundano" la pronuncia Jesús a rafz de una disputa sobre el poder nacido en el grupo de sus discipulos. Esto es precisamente lo que toma Jesús como punto de partida para pasar al ámbito de los suyos: "entre ustedes, que no ocurra eso". Y fundamenta esta enseffanza en la contraposición entre el poder "mundano" y el propio Jesús, que "no ha venido a ser servido, sino a servir" (LC 22, 27; Mc 10, 45) 2 .

Jesús no dice, pues, que la autoridad ya es (sin más) servicio, sino que el que la tiene debe comporiarse como el que sirve. $Y$ apela para ello no a su propio poder (que sería ya sin más servicio), sino a su propia conducta:, yo me comporto con ustedes como el que sirve ( $L c 22,27)$. Por eso, ahora que habla a los suyos, ya no utiliza los verbos anteriores (kyrieutô, o eksousiasdsô. sino verbos mucho más suaves: (o êgoumenos, o meidsôn).

Y desde aqui estamos, como acabo de decir, en el terna de la autoridad religiosa

\section{La autoridad religiose}

2.1. El capítulo 23 de San Mateo es demasiado conocido para que ahora podamos entretenemos en un analisis de sus contenidos que, en parte, he hecho yo mismo en otros lugares. Me limito, pues, a evocar el empetio de Jesús en que en su comunidad nadie tenga el nombre de autoridad, sino que lodos se llamen hermanos (vv. 8-10), y su advertencia de que las autoridades religiosas creen justificarse "colando mosquitos y tasando el diezmo de la menta y del comino". mientras se insensibilizan ante la "justicia y la misericordia", que constituyen la verdadera voluntad de Dios (v. 23).

Pero aqứ nos interesa más bien un análisis formal. Y éste pondría de relieve no sólo la libertad de espíritu y de palabra de que hace gala Jesús (véanse los latiguillos de su lenguaje: serpientes, hipocrilas, engendros de viboras, sepulcros blanqueados, ay de ustedes... ¡Nunca en todo el evangelio habia hablado Jesús de esta manera!), sino en estas otras dos observaciones: 
a) Escribas y fariseos son criticados en cuanto autoridades, y no (como suena hoy para nosotros) en cuanto "Ios malos" de la historia. Esto se muestra bien claramente por el verso 3 que introduce el discurso: "guarden y hagan las cosas que les digan".

b) Jesús, hablando asf, pone de relieve su absoluta decisión de que la autoridad en su Iglesia sea mucho más impecable que la autoridad civil. Esto se confirma además por el conterto vital en el cual (según los comentaristas) habria sido escrito este capítulo. En efecto, en la comunidad mateana habia problemas de estructuración y de autoridad.

2.2. Hay otro momento en el evangelio en el cual Jesús no simplemente habla sobre las autoridades religiosas, sino que se ve enfrentado a ellas. $Y$, para sorpresa nuestra, Jesús no se limita a hacer lo que le dicen, sino que exige a la autoridad que se acredite no sólo como autoridad formal, exterior, sino como autoridad interior. Se trala de la escena que sigue a la expulsión de los mercaderes (Mc 11, 27ss). Los "sumos sacerdotes, escribas y ancianos" preguntan a Jesús con qué razón y con qué libertad ${ }^{3}$ se ha permitido expulsar a los mercaderes. Jesús, en lugar de contestar, pregunta a sus interloculores: ya que ustedes dicen ser maestros, acrediten su magisterio contestando a una pregunta sobre el origen del bautismo de Juan. Cuando los sumos sacerdotes no saben contestar, Jesús se limita a decir que él ampoco va a contestarles a ellos. Y actúa ası́ públicamente: tras decir eso, "se puso a hablar a la gente en parábolas" (Mc 12, 1).

Personalmente, no considero que este comportamiento de Jesús pueda ser tomado como una pauta universal de conducta, puesto que Jesús está acuando aqul como hombre solo, y no como miembro de una comunidad. Pero, si no es pauta universal de conducta, sf es un indicio bien claro de la concepción jesuánica de la autoridad, que es lo que aquí buscamos.

2.3. Hay otras palabras de Jesús (en este caso más discutidas) que podrían revelar la misma exigencia de acreditación interior de la autoridad a que aludiamos en el apartado anterior. Se trata de la fórmula con que el Maestro despide a los leprosos curados, diciéndoles que se presenten a los sacerdotes eis martyrion ausois (Mc 1, 44; Mt 8, 4; Lc 5, 14). Esta fórmula admite una doble traducción. Una más neutra: "para que les sirva de testimonio" (es decir, para que puedan constatar tu curación y admitirte en la comunidad), y otra más polémica: "en testimonio contra ellos" (es decir, porque han utilizado su poder simplemente para declarar impuros a los enfermos, en lugar de intentar curarlos, que es la única justificación de todo poder. $Y$ el gesto de Jesús muestra que el marginado no es un impuro por el mero hecho de ser marginado). Los exegetas se dividen a la hora de interpretar estas palabras, y nosotros no vamos a tomar partido. Pero sf conviene sefalar, en favor de la traducción "polémica", que éste es, curiosamente, el significado innegable que tienen las palabras eis martyrion 
aufois las otras veces que aparecen en el evangelio: cuando los discípulos enviados no sean recibidos en alguna casa, deben limitarse simplemente a sacudir el polvo de sus zapatos "como testimonio contra ellos" (Mc 6, 11). Y cuando los discípulos sean llevados a los tribunales del poder pagano, eso mismo servirá de testimonio contra éstos (Mt 10, 18).

Concluyamos, pues; Jesús critica a las aubridades existentes porque éstas pretenden justificarse sólo por el hecho de llamarse bienhechoras o serviciales, pero no por ejercerse servicialmente. Y esta crítica vale con un enorme a fortiori para la aubridad religiosa, la cual, según Jesús, se desautoriza a si misma cuando su ejercicio pretende apelar a razones meramente formales, en lugar de a razones "diacónicas". Ahora hemos de pasar a ver cómo concibe Jesís ese ejercicio diacónico de la autoridad.

\section{La enseñanza de Jesús sobre la autoridad}

\section{A nivel normativo}

Ya es sabido que fue el evangelista Mateo quien elaboró más la normativa de una autoridad realmente servicial, probablemente porque escribe en un momento y a una comunidad donde se haclan sentir tanto la necesidad como los riesgos (recordemos lo que acabamos de decir sobre Mateo 23) de un ministerio de dirección en aquella Iglesia. Creo que su ensefianza puede réducirse a dos principios, al que affadiremos después un tercero, tomado de Lucas.

1.1. En primer lugar, deberemos hablar de la necesaria mediación de los marginados: cuando el juez supremo ejerza su juicio definitivo, juzgará desde su propia e inesperada presencia en los maltratados, no desde la relación innediata con él. O con otras palabras: lo que valdrá a la hora de la verdad es si "me dieron de comer" o "me visitaron" en alguno de mis hermanos más pequeños (Mt 25, 40). No valdrá, en cambio, el que hayan pretendido "comer delante de $\mathrm{ml}^{\mathrm{m}}$ (Le 13, 26) o hayan apelado a "mi nombre" para actuar (Mt 7, 22). O matizando más, todo esto segundo no valdrá si no está mediado por aquello primero. La autoridad es, pues, para Jesús el hermano de los marginados.

Aquí está Jesús en continuidad con aquel sector del Antiguo Testamento que dilucida la polémica entablada a propósito de la realeza, en la que unos querian ver la mediación de Dios (el rey serfa "el ungido") y otros véan sólo la traición a Dios ("es a Mí a quien rechazan"). Esta polémica no se acalla hasta que no aparece la línea mediadora (que representan, por ejemplo, muchos salmos) y para la que el rey sólo se justifica y no tiene otra razón de ser que la defensa de los indefensos: "juzgará al pobre que suplica, al afligido que no tiene protección, se apiadará del humilde e indigente y salvará la vida de sus pobres; rescatará de la violencia sus vidas, pues su sangre es preciosa ante sus ojos" (Sal 
71). Cualquier poder que pretenda justificarse de otro modo ya no puede apelar para ello al Dios de Jesús.

Precisamente por eso, Mateo se atreve a cambiar de contexto la parábola de Jesús sobre la oveja perdida, trasladándola ahora (del contexto "social" que ha conservado Lucas y en el que parece que la pronunció Jesús) a un contexto eclesial: la autoridad está para salir a buscar la oveja perdida, y sin esto se desvirtía su relación con la comunidad (ver Mt 18, 12ss).

1.2. En segundo lugar, y como ya se ha escrito muchas veces, la autoridad está para actuar sólo como uno instancia últime, no como instancia primera ni única. Esto es lo que parece reflejar el famoso consejo de Mateo 18, 15ss: las situaciones, incluso conflictivas, conviene que se resuelvan primero entre los interesados, o contando quizá con alguna ayuda exterior a ellos, pero no impositiva. Sólo si estos caminos fallan, se hará necesario el recurso a instancias de autoridad, que Jesús aquí no especifica, sino que formula con el nombre genérico de "la Iglesia". (Porque, si se produce tal fallo en los mecanismos espontáneos de la fraternidad, no será, probablemente, sin culpa de alguna de las partes interesadas.)

Este pasaje de Mateo es suficientemente conocido. Pero quizá no se ha seflalado con igual insistencia que estos consejos parecen ser una aplicación práctica de la extrafla doctrina que Jesús había expuesto sobre el escándalo pocos versos más arriba (ver Mt 18, 7-9): si tu ojo, tu mano o tu pie te escandalizan, arráncatelos. Para saber qué significa aqui "escandalizar", conviene atender a que estas frases están enmarcadas por una de esas típicas "inclusiones" bíblicas que giran en tomo al tema de los "pequefios". Las palabras de Jesús se han abierto con una advertencia contra "el que escandalice a uno de estos pequeflos" (v. 6) y se cierran con el consejo de "no menospreciar a ninguno de estos pequeños" (v. 10: el menosprecio o la falta de consideración son, evidentemente, la razón más profunda del escándalo, y aqư la penetración psicológica de Jesús resulta tan profunda como en otros muchos momentos). Jesús enuncia, pues, que va a hablar sobre cómo tratar a los "pequefios", y concluye diciendo que ha hablado de eso. Y en medio ¿qué ha dicho? Que vale más arrancarse el ojo o la mano y entrar mutilado en el cielo que ser echado enterito al infierno. Parece, pues, claro que el ojo o la mano significan aqui $e l$ poder sobre los pequefios, que cualquier persona puede tener de una manera y otra: si tu poder dafta a los pequeffos, despréndete de él's.

1.3. Y esta élica mateana sobre lo que puede significar el ejercicio servicial de la autoridad encuentra su fundamento en la clásica teologla lucana sobre la paternidad de Dios: según la parábola del hijo pródigo, la paternidad de Dios no estó para quitar libertades, sino para alegrarse por el regreso del hijo. La parábola cobra más fuerza por cuanto no se trata de la libertad del hijo bueno, sino de aquel de quien se puede temer que va a abusar de ella. Es claro que aqul 
Lucas habla inmediatamente de Dios, y que el hombre puede arguir que no sabe hasta qué punto eso es posible entre nosotros (yo mismo he dicho en otros momentos que esta parábola no pretende ser ningún tratado de pedagogia familiar). Pero es muy claro también que ese modo de ser de Dios marca la dirección y la meta hacia la que debe tender toda relación entre los hombres en la que intervenga cualquier forma de poder. Los poderes que los hombres podamos tener están sólo para transparentar en su ejercicio el ser de Dios, pero nunca para apropiarse a Dios ni siquiera con la excusa de defenderlo. Logicamente, esto es lo que no podían entender los escribas y fariseos a quienes se dirige la parábola (ver $L c 15,2)$.

$Y$ tras esta sistematización (evidentemente artificiosa) sobre lo que Jesús ensefia en general, o a niveles doctrinales, puede ser bueno intentar ahora rastrear lo que dice sobre si mismo, a nivel personal.

\section{A nivel de experiencia personal}

¿Qué piensa de sí mismo y de su actuación hacia los suyos aquel que dice "Yo estoy entre ustedes como el que sirve" (Lc 22, 26)? Otra vez es el evangelista Mateo -que, como ya sabemos, es el más atento a la estructuración de la Iglesia-, quien nos suministra dos importantes elementos de respuesta.

2.1. La autoridad como "ejemplo, descanso y fuerza". Una de las frases en que el Jesús de Mateo se presenta como más consciente de su autorided es aquella en que afirma que todas las cosas le han sido entregadas por el Padre, hasta el punto que nadie puede conocer cabalmente al Padre si el Hijo no se lo revela (ver 11, 27). Pues bien, esta afirmación de Jesús viene enmarcada entre otras dos: una en la que Jesús reconoce con alegría que el Padre también ha comunicado algo de Sí a los sencillos, en lugar de a los poderosos (11, 25); y otra en la que Jesús saca las consecuencias de esa donación del Padre (11, 2830).

¿Y cuáles son esas consecuencias? Aprendan de mf, porque soy manso y humilde. Vengan a mi los que andan agobiados. Y, por último: carguen con mi mismo yugo, porque es suave. La autoridad que Jesús siente tener quiere cjercerla con su ejemplo de sencillez, con su capacidad de alivio y con su promesa de fuerza. Hay aquí una radical inversión de la noción humana de autoridad, porque ésta, como escribió muy bien Maquiavelo, ha de ofrecer el ejemplo de ser "poderosa y fuerte"; no ha de buscar el alivio de los suyos, sino "el ser ternida" por ellos; y ha de "imponer sumisión", en lugar de ofrecer ayuda para los que quieran llevar su mismo yugo. "Mi yugo" no significa el yugo que yo impongo (porque entonces no se invitaria a "tomarlo"), sino el yugo que yo mismo llevo y que, por eso, puedo garantizar con la fuerza de Dios que se convierte en suave.

Cuando alguien intenta proceder asi ${ }^{ో,}$ hs cosas se ponen de tal modo del 
revés que, en primer lugar, se le dirá enseguida que "no sabe ejercer la autoridad" (que es lo que aquel gran inquisidor de la parábola de Dosloievsky le viene a decir a Jesús). Y, en segundo lugar, se intentará quitarle de en medio como sea. Pero también, sólo quien intente proceder asi, como Jesús, convertirá su autoridad en autorla respecto de los suyos; porque muchos de éstos le responderán con lo mejor de sí mismos y darán así lo mejor de sí mismos, en lugar de responder con lo peor del hombre: con el odio, el miedo, o la adulación que pone en práclica aquella hegeliana dialóctica del siervo y el señor?

2.2. Jesús quiere utilizar su autoridad para que los hombres sean misericordiosos, no para que le den cullo.

El pasaje de las espigas arrancadas en sábado (Mt 12,1ss) provoca una discusión sobre el ejercicio de la autoridad ("hacen lo que no está permisido"", $12,2)$. Mientras los otros evangelistas reducen la respuesta de Jesús a una reflexión sobre la dignidad del hombre, señor del sábado, Mateo afiade a esa frase otra reflexión de Jesús sobre su autoridad, sobre lo que él "quiere". En esta reflexión, Jesús se apropia la frase de Oscas: "misericordia quiero y no sacrificios". El objelivo de la autoridad de Jesús es, pues, la misericordia que crea fraternidad entre los hombres, no la afirmación de su propio poder. Precisamente por eso (y asi continúa la escena), Jesús decide curar provocativamente en sábado. Y digo "provocativamente" porque es verdad, como decía uno de los jefes de la sinagoga, que muchas curaciones no eran urgentes y que se habría podido esperar a un día "laborable". Al no hacerlo, Jesús pasa a un segundo lugar, porque pone en entredicho su propio poder taumalúrgico (se podrá decir de él que "no viene de Dios, puesto que no guarda el sábado"). Pero, al pasar su poder a segundo plano, queda en primer término la misericordia, que es la que no puede esperar.

Pero si una autoridad decide realmente que ella está para que los hombres sean hermanos y no para que le rindan culto, el "orden" de este "mundo" se subvierte de tal manera que no se hace esperar el resultado de toda esta secuencia: "tomaron la decisión de acabar con él" (Mt 12, 14).

2.3. Este resumen de la enseñanza de Jesús puede cerrarse con otro texto, lógicamente también de Mateo: esa autoridad que Jesús ha tratado de enseñar es la única que él transmite a los suyos, puesto que "para el discípulo ya es bastante ser como su maestro, y para el esclavo ser como su señor". Pues "no es un discípulo más que el maestro, ni un siervo más que su amo" (Mt 10, 24-25).

Como es sabido, a veces Jesús echó mano de relaciones laborales de su época (que no eran precisamente modelos de justicia interhumana) para ilustrar la relación del hombre con la voluniad de Dios, pero nunca para aplicarlas a la autoridad humana, ni siquiera a la autoridad religiosa. Por eso, el mismo Jesús de los sinópticos se presenta siempre como totalmente referido y totalmente obediente al Padre, pero nunca como ocupando el lugar del Padre. Pues el 
hombre está plenamente referido a la voluntad de Dios, pero, precisamente por eso, no está totalmente referido a ninguna voluntad humana, ya que ningún hombre tiene poder sobre "el alma" humana (Mt 10,29)". Por eso puede ocurir a veces que el seguimiento de Jesús separe al hombre de su padre o a la hija de su madre $(10,35)$.

La conducta posterior de los primeros cristianos, cuando contraponen la obediencia a Dios y la obediencia a la autoridad religiosa ("los hombres": ver Hechos 4, 19 y 5,29), o cuando se niegan a aplicar al emperador el grado de vinculación que expresan para con el resucitado (Kyrios lêsous, pero nunca Kyrios Kaisar), incluso aunque esto les cueste el castigo o la vida, es una pucsta en acto de esta enseffanza.

Y, al hablar de puesta en aclo, estamos ya en el tema de la praxis, que ha de ocupar la parte central de este trabajo. Ahora nos interesa la praxis de Jesús. Y si para su ensefíanza nos ha sido más útil el evangelio de Mateo, serán Marcos y Lucas, como es logico, quienes más información nos suminisuren sobre esta praxis jesuánica a la que remile la conclusión mateana: que no puede ser el discípulo más que el maestro.

\section{La praxis de Jesús}

\section{El empeño en un lenguaje asertivo}

Con una especie de aproximación borrosa, podemos comenzar seffalando que el lenguaje de Jesús en el ejercicio de su autoridad parece como si tratara de cumplir en el campo del poder aquel conscjo del propio Jesús: "que vuestro lenguaje sea sí sí, y no no, porque lo que pasa de esto proviene del Maligno" (Mt 5, 37).

De acuerdo con esto, Jesús no impone, no increpa, no intimida, y rara vez manda o reprende. Hay excepciones, que luego analizaremos. Pcro la abrumadora mayoría de los textos transmiten como lenguaje habitual de Jesús la fórmula "yo les digo" (o en forma narrativa: Kai, legei, kai eipen). Tal uso, abrumadoramente mayoritario, es común a los cuatro evangelistas, y esto constituye también un detalle llamativo. Y, por supuesto, muchas veces se explica simplemente por la naturaleza misma de lo narrado, que no demanda ninguna acción autoritaria. Pero otras veces, el verbo decir, en labios de Jesús, sirve más bien parafrasear algún imperativo ${ }^{10}$.

Como es también sabido, este "decir" de Jesús aparece con frecuencia reforzado por la palabra amen (Lucas, que escribe para griegos, prefiere decir aleshôs, en verdad, o nai). Es un modo de subrayar que la autoridad de las palabras de Jesús radica en la verdad misma de lo dicho, no en el modo autoritario de decirlo, ni siquiera en la persona que lo dice. Del mismo modo, es frecuente que, a la hora de proponer una decisión, Jesús no imponga direc- 
tamente, sino que pregunte o espere a ser preguntado, o simplemente pida (ambas cosas con el verbo erôtấ, que es el que suelen utilizar las gentes para dirigirse a Jesús)" ${ }^{11}$.

Dentro de este contexto, es perceptible también en los evangelios que las palabras más duras de Jesús no están dichas a personas particulares, sino a grupos o colectividades. Asf, la única vez que encontramos al Jesús terreno como sujeto del verbo reprender (oneididsô), es para referirse a las ciudades de Betsaida y Corozain por no haber hecho penitencia, a pesar de los milagros que hablan visto (ver Mt 11, 20).

$Y$, finalmente, he seftalado al comienzo de este apartado que el afán de Jesús por un lenguaje meramente asertivo tenia algunas excepciones que vale la pena analizar, porque sus contenidos son reveladores. Veamos algún ejemplo.

En los evangelios sólo una vez se nos dice que el Jesús terreno "mando" algo (con keleuô). Se trata de la escena del ciego de Jerico, al que la gente estaba "intimando" para que se callase (con el verbo epitimeô que veremos ahora mismo). Compárese este uso con el de Mateo 18,25 , cuyo sujeto ya no es Jesús, sino uno de los poderosos de este mundo.

En dos ocasiones, Jesús "habla con severidad" o "reprende" (Mt 9, 30 y Mc 1, 43: embrimasthai). Y ambas tienen que ver con el secreto mesiánico o la prohibición de difundir sus curaciones. Este detalle volveremos a encontrarlo ahora mismo. De momento, basta con sugerir otra comparación con un uso no jesuánico del término (Mc 14,5) que obliga a Jesús a intervenir en defensa de la mujer atacada.

Finalmente, cabe considerar en los evangelios todavia un par de verbos que tienen un sentido formalmente imperativo: diastellô (disponer, con el sentido de "decidir") y paraggellô, más suave que el anterior (anunciar, con el sentido de "promulgar"). Pues bien, otra vez encontramos que el primero de estos verbos es usado por el Jesús terreno para cuestiones que tienen que ver con el secreto mesiánico: no decir quién era él o no publicar algún milagro'i2. Por lo que toca al verbo paraggello, los usos ya no son tan constantes, salvo en Lucas, quien lo utiliza siempre para referirse al secreto mesiánico (ver 5,$14 ; 8,56 ; 9,21)^{13}$.

Parece, pues, dibujarse la conclusión que Jesús impone con autoridad sólo cuando eslá en juego la defensa de algún marginado o la falsificación "gloriosa" de su mesianismo. Con todo, hay que repetir que estas observaciones son sólo aproximativas, como grandes manchas de color. No solo por la óptica postpascual de los evangelistas, quienes a veces han proyectado sobre el Jesús terreno la condición del resucitado, sino, sobre todo, por lo elástico que tiene que ser todo lenguaje narrativo a la hora de introducir diálogo. Pero es esta elasticidad la que hace más llamativa la confluencia que hemos ido descubriendo en este primer apartado. Y lo que la refuerza de modo 
sorprendente es el análisis del verbo epitimấ, que tiene ya un carácter mucho más técnico y más definitivamente establecido. Con él estamos en un punto central de este trabajo.

\section{La intimación}

Se suele pensar que lo más decisivo de toda autoridad es el poder de intimar. Esa intimación se expresa en griego con un vocablo bastante consagrado: el verbo epiriman, en cuyo significado confluyen a la vez los matices de imposición, de reprensión y de honor del sujeto que lo ejerce. Más alla de las posibles traducciones (intimar, conminar, increpar otras veces...), epitiman da nombre exactamente al derecho de los sehores. Y quizás tenemos en los mismos evangelios una buena descripción del significado de este verbo en to que pensaba precisamente una autoridad pagana: le digo a uno ven, y viene; haz esto, y lo hace (ver Mi 8, 9). Así de mecánico's4.

Pues bien, hay algo llamativo en el uso de este verbo que los evangelios asignan a Jesús. Y creo que se vuelve más llamativo por comparación con el uso que hacen de él las demás gentes.

Habitualmente, los hombres se increpan mucho entre sí, comportándose los unos como seffores de los otros: los discípulos increpan a los niffos (Mt 19, 14; Mc 10, 13; Lc 18, 15). La gente conmina a los ciegos (Mt 20, 31; Mc 10, 48; Lc 18, 39). Desde la cruz, un ladrón increpa al otro (Lc 23, 40). Los fariseos le piden a Jesús que reprenda a sus discípulos $(L c 19,39)$. Y el mismo Pedro, ante el anuncio de la pasión, increpa también a Jesús (Mt 16, 22; Mc 8, 32). Siempre con el verbo epitiman.

Pues bien, en Jesús el uso habitual de este verbo (con las excepciones que ahora mismo sefalaremos) no va dirigido a otras personas, sino a los demonios (Mc 1, $25=$ Lc 4, 35; Mc 3, 12 = Lc 4, 41; Mt 17, 18 = Mc 9, 25 o Lc 9, 42), a las fuerzas de la naturaleza (Mt 8, 26= Mc 4, $396 \mathrm{Lc} \mathrm{8,24)} \mathrm{y} \mathrm{a} \mathrm{la} \mathrm{fiebre} \mathrm{(Lc}$ 4,39 ). Es decir, a las fuerzas que oprimen al hombre y que son, por eso mismo, los verdaderos enemigos del reinado de Dios. Estos son los verdaderos objetos de la autoridad y del poder también entre los hombres, pero mucho más cuando se pretende transparentar a Dios.

Este uso es además constante en los tres sinopticos, como se ve por las cilas aducidas, y sin que esta constancia se deba siempre a que dependan unos de otros. Además, hay veces en que la diferencia entre la conducta de Jesús y la de los hombres queda resaltada por el contraste, en un mismo pasaje, entre el epitimousi de las gentes y el simple "decir" de Jesús (ver Mc 10, 13 con 10, 14; Lc 19, 39 con 19, 40; Mc 10, 48 con 49). Los hombres suelen ejercer la autoridad imponiendo; Jesús no.

$Y$ sin embargo, como ya hemos insinuado al enunciarlo, hay momentos 
excepcionales 15 en que Jesús cambiên "intima" o reprende a las gentes; y lo hace prócticamente siempre en relación con el llamado "secreto mesiánico": para que no se le descubra o se falsifique su mesianismo (ver Mt 12, 16: al pueblo; Mc 8, $30=L c$ 9, 21: a los discípulos, o Mc 8, 33: a Pedro) ${ }^{16}$. Las perversiones de su identidad mesiánica son para Jesús algo demoníaco (como muestra el pasaje de las tentaciones de Mateo), y por eso, el uso excepcional de epitiman en estos pasajes tiene un sentido literalmente "exorcista" (como se ve por el duro calificativo de "Satanás" que Jesús dirige a Pedro).

Y si el análisis anterior nos acerca a una aclitud original de Jesús, quizá podría confirmarse ese resultado con dos verbos que son como el reverso de la medalla: a) la expresión "no prohiban" (me kôlyete), que una vez aparece incluso como respuesta de Jesús a una acción de epitiman por parte de los discípulos (ver Mi 19, 14 y paralelos; y además Mc 9, $39=$ Lc 9, 50). Y b) la formula "no teman" (o no lemas), que parece provenir de la fuente $Q$ y que se halla en diversos contextos en labios de Jesús: el discípulo no deberia temer ni a las autoridades mundanas (Mt 10, 26; Lc 12,4) ni a las fuerzas naturales (Mt 14,27 ; Lc 5, 10) ni al desamparo habitual del hombre $(L c 12,32)$. Y Jesús subraya como razón el valor del hombre para Dios (Mt 10, 31; Le 12, 7). Una vez más parece que, mientras los hombres nos relacionamos intimándonos unos a otros (y mucho más cuando disponemos de alguna parcela de poder), Jesús ejerce su auloridad, evilando la prohibición y disipando el temor.

\section{La eksousía}

De momento es necesario mantener esta palabra en griego, dada la enorme ambiguledad del término. Se trala además de una de las palabras más presentes, tanto en los evangelios como en el resto del Nuevo Testamento. Y significa, a la vez, autoridad y libertad (etimológicamente, el verto eksesti suele traducirse como "es lícito"). Pero quizá sólo en Jesús encontramos la síntesis de ambos significados.

En el resto del Nuevo Testamento, eksousia sirve para designar unas veces la libertad de los cristianos (por ejemplo, 1Cor 6,$12 ; 8,9 \ldots$..). Pero otras muchas veces alude a poderes ilegítimos: el poder de Satands (Hchs 26, 18; ver $L c 4,6$ ), el poder del Anticristo o de "la bestia" (Apoc 13,2.4) y el poder de los espíritus o de las tinieblas (Ef 2, 2; Lc 22, 53).

Pues bien, si esta oposición de significados sorprende, es aún más llamativa la unión de ambos en Jesús. En él, autoridad y liberad son lo mismo. La autoridad de Jesús es, precisamente, su profunda liberad. Y ésta es la esencia de loda verdadera autoridad evangélica: una fuerza interior que supera las barreras o coacciones exteriores y que es como una variante de la misma dynamis con que Jesús obra sus milagros. Así, la autoridad de la palabra de Jesús proviene de su misma libertad, y esto la vuelve asombrosa para las gentes. Pero también la 
naturaleza. Y cuando los fariseos reclaman de Jesús una acredilación exterior de su autoridad, Jesús se niega a darla, porque su acluación se legitima por la razón interior de su propia libertad ${ }^{17}$. Esto, evidentemente, es lo contrario de todos aquellos "poderes de la tierra" (ver Lc 22, 25ss) a los que Jesús ordena "no imitar", por cuanb su dominio proviene de su falta de libertad. Pero, a la vez, esos poderes mundanos se ponen en evidencia a sí mismos y dan la razón a Jesús cuando a su falso dominio lo llaman "servicial" o "bienhechor". Porque con ello reconocen, sin querer, que la verdadera liberad del hombre es la libertad para servir y que en el servicio al hermano es donde coinciden autoridad $y$ liberad.

Y el últino aspecto de este apartado es que, según los evangelios, este poder de la eksousía es el que Jesús transmite a sus apóstoles: "les dio autoridad frente a los espíritus inmundos, frente a la enfermedad y la debilidad" (Mt 10, 1; Mc 6, 7; Lc 9, 1), frente a los demonios (Mc 3, 15) y frente a las fuerzas de la naturaleza y "del enemigo" (Lc 10,19). Aụnque todo don de Jesús no es para el hombre una posesión, sino un camino, en el que sólo se avanza en lucha contra la resistencia de la "calamidad presente", sin embargo, el seguidor de Jesús no debería pensar que no ha recibido de Jesús ninguno de esos "poderes" cristologicos y que, en cambio, ha recibido de él otros poderes "mundanos". Porque esto serfa falsificar el apostolado.

\section{Ed reflejo del lenguaje en escenas concretas}

Todo lo anterior parece encontrar unos ejemplos llamativos en algunos momentos de la conducta de Jesús. El primero es la acción simbolica realizada por Jesús en el Templo de Jerusalén (Mt 21, 12ss; Mc 11, 15ss): una de sus acciones más radicales de poder, y hasta más "autoritarias" si se quiere, la realiza Jesús no "desde arriba" y como autoridad, sino "desde abajo" y como critica. Cabe reconocer que no es sino muy lógica la reacción de los sacerdoles y los escribas al preguntarle con qué autoridad hace aquellas cosas (Mc 11, 27 par.). Pero Jesús no quiere ampararse en ningún poder formal o exurfnseco, porque entonces, en el mejor de los casos, su actuación habría sido aceptada "por la fuerza" y no por la verdad de la ensenanza sobre cú́l es el verdadero templo de Dios, que Jesús quería transmitir con aquella actuación.

El ouro ejemplo voy a titularlo intencionadamente "las conferencias de prensa" de Jesús. Leamos aquí el capítulo 22 de Mateo, por ejemplo: "Presentándose como un hombre cualquiera" (ver Fil 2, 7); sin más autoridad que la de su palabra y la verdad de lo que dice, Jesús no rehuye a un solo interlocutor y accede a todas las preguntas, a pesar que el evangelista nos informa de la mala intención con que se le preguntaba muchas veces y quería poner en juego el clásico recurso de acusación de heterodoxia como una respuesta a una crítica ${ }^{10}$. Y al final resula que "nadie se atrevía a preguntarle", no por el mal genio de su 
Y al final resulta que "nadie se atrevía a preguntarle", no por el mal genio de su poder, sino por la capacidad de convicción de su verdad (Mt 22, 46). Claro está que semejante modo de ejercer la autoridad tiene un precio, y es "la decisión de cabar con $\mathrm{el}^{\mathrm{n}}$, tomada por los poderes de este mundo.

Y quizés hay que afladir, para cerrar este comentario, que Jesús de ningún modo era un presuntuoso, y que nosotros tampoco debemos serlo. Quizá la verdadera diferencia entre él y nosotros reside en que él no tenía nada que esconder, y nosotros siempre tenemos algo (o bastante). Pero precicamente ahí esta la razón de por que su libertad era autoridad, y la orientación del camino que el seftala para nosotros.

\section{Conclusión: la autoridad del amor}

En resumen, el que tenía poder para mandar a los demonios procuró no mandar a los hombres, sino que trató de convertir su libertad. Y el que será confesedo como sujeto de "todo poder en el cielo y en la tierra" procuró no hablar dictando, sino convenciendo, de modo que la gran autoridad de su palabra no brotara de fuera de ella (la Ley o la apelación al mismo Dios), como en los escribas y fariseos, sino de ella misma.

Pero hay que afladir que precisamente así es como Jesús reveló y puso en préctica la relación de Dios con los hombres. Esa renuncia a "retener ávidamente su imagen divina" (Fil 2, 6ss) es lo que transparentó a los hombres el amor liberador de Dios. Como escribe Hans Kessler:

Las calegorias de poder y soberanla sufren de ese modo una inversión radical y una redefinición decisiva. El concepto de poder suele designar la capacidad para influir en otros dentro de una determinada esfera, conforme a la propia voluntad, de tal suerte que no pueden escapar a esa influencia. Y la soberanfa designa el ejercicio de tal poder (independientemente de que sea justo o egocentrico y represivo). En este sentido el Crucificado resucitado y elevado no posee ningún poder ni sefiorio. Es posible escapar a su influencia y rehusarla. Es verdad que êl no es impotente ante los hombres y ante el mundo. Pero su poder es de otro género. Es el poder del amor que se despoja y se entrega, que no obliga por la fuerza ni esclaviza sino que retrae -impotente en apariencia-, deja libre al otro y que se haga valer, pero al mismo

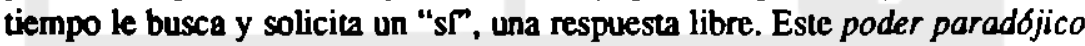
(que, oculto bajo su contrario, la extrema impotencia, procede desde abajo, precisamente como amor), sólo prevalece si los ouros se abren a él libremente (y asf comienzan a ser para los demás). $Y$ sin embargo, este poder - en virtud de su renuncia a la auloimposición y de su apuesta por los otros- posee paradojicamente una fuerza persuasiva peculiar, un fuerte cartcter vinculante y un poderio interno. El poder de Jesucristo es... 'el amor que busca' el poder de una oferta liberadora, el poder del nego ${ }^{19}$. 
$Y$ de esta conclusión se siguen las dos reflexiones práclicas que anunciábamos al comienzo de este articulo: una sobre los seguidores de Jesús, y otra sobre los resultados de Jesús.

\section{Autorided y seguimiento de Jesús}

"Todo el que invoca y confiesa el nombre del Sefior resucitado será salvo. Pero invocar y confesar al Sefior implica transparentar en la propia vida su manera especlífica de ser señor "20.

Efectivamente, a lo largo de nuestra exposición han ido surgiendo referencias a la vinculación que hay entre lo que Jesús hace, en su concepción y su ejercicio de la autoridad, y lo que Jesús ensefia a aquellos a quienes llama y envla Pero si lo de Jesús implica realmente "un mundo al reves", ¿cómo potremos nosotros, pobres hombres, habémoslas con ese mundo al revés?

$Y$ a esa pregunta hay que responder que, en primer lugar, no desautorizando a Jesús, sino dejándonos juzgar por él. Lo primero sería sólo la respuesta del gran inquisidor de Dostoievsky y, desgraciadanente, ha sido más de una vez la respuesta de la Iglesia. Lo segundo es lo que se nos invita a hacer, precisamente porque el juicio de Dios en Jesús es juicio de acogida y de transformación. Dejándonos llevar y transformar por el Espiriu de Jesús, podremos comenzar a caminar en su nueva dirección.

Y ese comenzar a caminar es el segundo punto de nuestra respuesta. ¿Hasta dónde? No lo sabemos. Pero de lo que se nos pedirá cuentas no es de hasta dónde hemos llegado, sino en qué dirección hemos ido caminando. Ya he hablado varias veces de que la meta de Jesús significa para nosotros la dirección del camino (o en formulación teológica más técnica: que la divinidad de Jesús implica el don del Espíritu para nosotros). Pues precisamente aquel mismo que distingula siempre entre "mi" Padre y "vuestro" Padre no conclufa de ahl que ustedes no puedan "ser perfectos como el Padre celestial" sino, sorprendentemente, lo contrario (ver Mt S, 48).

Sólo queda, pues, repetir con el salmista: "ojalá escuchen hoy su voz".

\section{El rechazo y el triunfo del amor}

También, a lo largo de la exposición anterior, se ha ido insinuando cuántas veces la conducta o la enseflanza de Jesús provocaban, paradójicamente, que se tomase la decisión "de acabar con él". Esto hay que recordarlo tambiên, al concluir, para no caer en ninguna ingenuidad mesiánica como la de los primitivos apostoles. De mil modos se nos repite también a nosotros la profecía de que "el Hombre ha de padecer y ser ninguneado" (Mc 9, 12) ${ }^{21}$.

El seguidor de Jesús ha de contar con eso sin llamarse a enganio. Ha de saber verlo también como una dura revelación de lo que somos los hombres y que la 
nos afecten inmediatamente a nosotros mismos, reclamemos respeto y amor a la libertad. Pero es innegable también que, acuando afecta a los demás, todos los hombres sentimos más admiración por la fuerza que por el respeto y el amor a la libertad. Y quizá tenemos aquí una de esas "opciones valorativas" (o de "normas previas") que, según Kant, configuran después nuestras conductas erróneas y constituyen nuestro "mal radical".

Por eso, a lo largo de la historia han triunfado siempre (aparentemente al menos) los poderes y autoridades contrarios a lo que aqui hemos descrito. Pero precisamente, ese triunfo es el que ha llevado a la humanidad al trauma de la autoridad con el que hemos abierto este artículo. Jesús, en cambio, con su renuncia al poder, ha obtenido en la historia unas cotas de seguimiento, de obediencia y de entrega muy superiores a las de cualquier otro personaje de esta historia. Aquel que es llamado "el Hombre" obtiene de este mundo, a la vez, verdugos y seguidores.

En este contexto, sólo queda repetir a todos los seguidores de Jesús, pero muy especialmente a aquellos que tenemos alguna parcela de autoridad del tipo que sea, no solo las palabras del salmó con que cerrábamos la conclusión anterior ("ojala escuchen hoy su voz"), sino también aquellas otras del Maestro que parecen a veces perfectamente olvidadas: "Soy yo. No teman" (Mt 14, 27).

\section{NOTAS}

1. Y ya se que el decir que Jesús es la única autoridad no equivale a negar que el axeso a Jesuls tenga mediaciones: sólo insinúa que esas mediaciones están sólo pera llever hasu El, nunca para sustituirle.

2. Con ello ya se ve que, cuando en el texto hablo de autoridades "mundanas", no me refiero a las que existen fuera del mundo religioso, sino a las que están fuera del reino de Dios. En ese sentido, una autoridad civil que intente ejercerse (no sólo fundementarse) servicialmente puede quedar más cerca de Jesús que un poder religioso que no se haya convertido en servicio. Este es el incuestionable valor cristimo de la democracia, aunque siga siendo verdad que "la Iglesia no es una de. mocracis", porque tiene "un solo Serior", que no es el pueblo, sino Jesucristo. Pero, precisamente por eso, tampoco puede ser la Iglesia una monarquía absoluta.

3. Sobre esta doble traducción de la palabra eksousía, véase lo que diremos más adelente.

4. Como primera de estas parabolas cuenta Marcos la de los malos viñadores. Y aquí ven muchos exegetas una velada respuesta a la pregunta que Jesús no había querido contesur. los sumos sacerdotes y escribas son incapaces de reconocer a los proletas y anviedos de Dios; por eso le vienen ahora a Jesús con preguntas de acreditación formal (ver, sobre bodo, Mc 12, 12).

5. Para que se ven cómo podemos los hombres llegar a manipular el evangelio (sobre todo desde posiciones de poder), me permilo evocar la siguiente anécdota El papa Pó II en su diario, justificaba sus guerras a muerte contra Segismundo Malatesta, atuciendo las citadas palabras de Jesús sobre arrancar el ojo o la mano. Por 
supuesto. Malatesta no era precisamente un san Luis Gonzaga Pero llegar a pervertir las palabras que Jesús habla dicho con un sentido un personal (referides claramente a it propio ojo o tu propia mano), para darles un sentido social (como si Malatesta fuera simplemente el ojo o la mano del papa, que kate "se arrancaba" con gran dolor (!). es cosa que no puede hacerse, sino desde la divinización de uno mismo por la propia autoridad. Por eso ya no extraina que Pb II contimbe agumentando que, si Malatesta hubiese pecado soblo contra el (contra Pio II), le habrin perdonado; pero habfa pecado contra Dios al agredir a la iglesia de Rome, y por eso no podla quedar sin castigo. (Ver Pii II Commentarii rerum memorabilium quae temporibus suis contigerunt, Citl del Vaticano, 1984, I. 624). Y repito que no siento ninguna simpatóa por el pequeío monstro que parece debib eer Segiemundo. Pero que un papa argumente de esa manera me parece una manipulación del evengelio que hoy resulta sobrecogedora

6. Y escribo simplemente que "intents", para dejar el espacio debido a aquello que Pablo llamaba la anake enestosa: la dura calanidad de la sibueción actual.

7. Es posible que este pasaje de Mateo resuene en le reflexión misionera que cierra au evangelio ( $c f$. Mi 28, 18-20), aunque éstas ya no sean palabras de Jexís, aino de la Iglesia primitiva El hecho es que de la afimación del pleno poder del resucitado sobre cielo y tierra no se sigue más que une únice consecuencie: la mystagogá ("hacer discípulos"). Nuestros comentarios habituales presentan tres conseculencis, pero en el original griego no hay en realidad más que un imperativo: hagan discípulos. Y lo que sigue son dos participios que explicen el sigrificado de ese imperativo: "sumergir en el Padre, el Hijo y el Esplrio" (lo que se exprese en el beutismo, pero afecta a toda la vida del discípulo) y la consecuencia de eso: "enseñar a guardar". Esta fórmula parece un eco de las palabras de Jesurs sobre al propio yugo en Mt 11, 29-30, puesto que no habla de "imponer para que guarden" (¡desde fuera!), sino de "enseñar ormo se guarda" (ןdesde dentrol), que es precisamente lo único que nunca hace la autoridad "mundana". Oura vez estamos, purs, en el campo de la mystagogía.

8. Sobre la presencia de la misericondia en muchos relalos de curaciones (el celebre úpico narrativo de "las entrañas conmovidas"), remito a mi estudio sobre los milagros de Jesuls: Clanor del reino, Salamanca 1982.

9. La contraposición con el "cuerpo" hace sospechr que "alma" no tiene aquf el sentido semítico de "vida", sino que alude más bien a la intimided espiritual o personal del ser humano.

10. Las referencias serían inacabables. Ciñéndonos s6lo a los casos en que el "yo (les o te) digo" parafrasea algún imperativo, he aquí unos pocos ejemplos a vuelaplume" Mt 6, 2-25; 10, 42; 17, 20; 18, 3.19; 21, 21; Mc 9, 41; 10, 29; 11, 23; Lc 12, 37. 44; 18,$17 ;$ In 12,$24 ; 14,12 ; 16,23 .$. Para Jian, de lodos modos, entí muy clare deade el comienzo la autoridad única de Jesús comno Hijo Unigenito.

11. Ejemplos en Le 5, 3; Mc 8, 5.

12. Cf. Mt 16, 20; Mc 5, 43; 7, 36; 9, 9. La única excepción la constiuye Mc 8, 15: "Les dio órdenes diciendo: gúrdense de la levactura de los fariseos".

13. Le 8. 29 no constituye excepción, pues Jesús no se estú dirigiendo a pereonas, simo a los demonios. En cambio, Marcos usa este verbo para las normas que acompañan al envío de los discípulos $(6,8 ; 10,5)$ y. cuando la multiplicación de los panes, pare hacer sentar a la gente $(8,6)$. 
hecer sentar a la gente $(8,6)$.

14. Todavía en el Nuevo Testamento, encontramos equel extratio pasje de la certa de Judas (v. 9) en que el mismo sen Miguel no se atreve a epitinan a Sation, y deja que lo haga Dios...

15. Son los momentos que, como ya hemos dicho, marcen le ausencie del reino y le hora de esa "calamidad presente" de la que habla Pablo (1Cor 7, 26).

16. Unica excepción al tema del secreto mesif́nico me parece que es Le 10, 55: Jesús increpa a los disefpulos cuando Esos pretenden que baje fuego del cielo para consumir a las ciudades de Samarfa que no les han recibido. En renlidad, lo que pretenden los discípulos es otra falsificeción prictica del podar y de la mirión de Jesús. (Finalmente, en L 17,3 Jesurs aborizarta a increper al hemano que peca contra uno. antes de recurri a la autorided; pero la version mus primitiva de Mateo usa aqư elenchô en luga de epitimaô.)

17. Agrupando los lextos evengélicos, encontramos, por unto, que la elsousta re atribuye a Jesús unas veces en relación a le verdad de su palabre (Mt 7, 29; Mc 1, 22. 27; Lc 4, 32); otras veces en referencin a la liberted de su obra (Mt 21, 232437; Mc 11, 28.29.33; Le 20, 2.8); y otras en relación a su poder frente al demonio, el pecado o la enfermeded ( $L$ c 4, 32; 5, 24; Mc 2, 10; Mt 9, 8). En eate filtimo punto volvemos a encontrar lo dicho al hable del verbo epitinan.

18. Es inevitable la alusión comparativa a esas "conferencias de prensa", tentes veces más o menos amañanadas, de muchos poderes "mundmos", polĺicos o religiosos.

19. La resurrección de Jesús ( Salamanca 1989) 289.

20. Ibid. 293. Los subrnyados son mlos en estr cita y del autor en le anterior.

21. "Ningunear" es la traducción literal del vabo griego (eksoudeneô) que aparece en este pasaje. Es además una palabra que aprendi del argot anvadoreib, en equel pals donde tantos hijos del hombre y seguidores de Jesús son exectamente reducidos a la nada. Lo utilizo aquí como homenaje a Ignacio Elacurin y sus compafieros mtrtires. 